\title{
3 Research Square

\section{Intestinal obstruction in a tertiary care centre in India: are the differences with the Western experience becoming less?}

Suvendu Sekhar Jena ( $\sim$ suvu1078@gmail.com )

Sir Ganga Ram Hospital https://orcid.org/0000-0002-3072-0418

Ravi Chandra Reddy Obili

Sir Ganga Ram Hospital

Sri Aurobindo Prasad Das

Sir Ganga Ram Hospital

Ruchir Bhavsar

Sir Ganga Ram Hospital

Sanket Solanki

Sir Ganga Ram Hospital

\section{Samiran Nundy}

Sir Ganga Ram Hospital

Research article

Keywords: Intestinal obstruction, Adhesion, Carcinoma, Tuberculosis, Mortality

Posted Date: March 22nd, 2021

DOI: https://doi.org/10.21203/rs.3.rs-204690/v1

License: (c) (1) This work is licensed under a Creative Commons Attribution 4.0 International License.

Read Full License

Version of Record: A version of this preprint was published at Annals of Medicine and Surgery on December 1st, 2021. See the published version at https://doi.org/10.1016/j.amsu.2021.103125. 


\section{Abstract}

Background: Patients with intestinal obstruction consist of a major proportion of emergency room visits and the complication is associated with significant morbidity and mortality. It has a diverse etiology and varies from region to country. In developed countries it is mainly due to adhesions and in developing countries due to obstructed hernias. Although there are numerous studies from the western world there have been few recent publications from the developing world.

Method: We retrospectively analyzed all the patients admitted for intestinal obstruction to our department from January 1996 to December 2019. Their demographic data, duration of symptoms before presenting to the hospital and duration of stay before surgery in the hospital were noted along with cause and level of obstruction. The type of procedure, any post-operative complications, mortality or re-exploration were also noted. Post-operative complications were graded as per Clavien Dindo classification.

Results: A total of 986 patients presented with intestinal obstruction during this period out of which 743 patients underwent surgery. There were $429(57.74 \%)$ males 314 (42.26\%) females who had a mean age of 50.1 years (range 11 to 96 years). The commonest cause of obstruction was adhesions in $273(36.7 \%)$ followed by carcinoma [130(17.5\%)], tuberculosis [111(14.9\%)], stricture [94(12.7\%)] and hernia $(5.4 \%)$ patients. Colorectal surgery was the most common previous procedure in the adhesive group [85(31.1\%)]. Colon cancer was the common cause in carcinoma group. lleum was the most common site of obstruction [329(44.3\%)]. The overall operative mortality was 41 (5.5\%).

Conclusion: Postoperative adhesions are now the commonest cause of intestinal obstruction in our referral center with a comparable mortality rate with western reports. Though the etiology of intestinal obstruction is shifting towards the western pattern, tuberculosis, obstructed inguinal hernia still consists a major chunk of patients in developing countries.

\section{Introduction}

Despite being one of the most common surgical emergencies, intestinal obstruction even today is often difficult to manage and is associated with significant morbidity and mortality. Its etiology differs not only between countries, at times across different regions of the same country. Adhesive obstruction has been reported to be the most common reason for intestinal obstruction in Western countriessince the end of the last century while obstructed hernias are continuing to be the most common cause in developing countries. ${ }^{[1,2,3,4]}$ Though the mortality has now decreased from $60 \%$ to less than $10 \%$ over the last century due to advances in diagnostic and operative technique along with postoperative intensive care, but there is considerable variation with age and different etiological diagnoses. ${ }^{[5,6]}$

Although there have been numerous reports on intestinal obstruction from western countries there are very few publications from the developing world.There is stark difference not only in etiology, treatment but also the management resources between both. ${ }^{[7,8,9]}$ Nevertheless, with the improvement in living standards and better access to health care facilities, previously reported causes and outcomes of 
intestinal obstruction from developing countries might be changing, particularly for patients admitted to tertiary care hospitals in larger cities which might be towards the western pattern. Because of the emergency nature of presentation and associated risk of bowel strangulation prompting emergency surgery, an early establishment of cause and diagnosis is of paramount importance for prevention of morbidity and mortality.

With this in mind, this retrospective study was conducted in our department, a tertiary care centre in India with patients who presented with intestinal obstruction over 23 years, and results were compared with those reported from western countries.

\section{Patients And Methods}

We retrospectively analyzed all the patients admitted for intestinal obstruction to the Department of Surgical Gastroenterology and Liver Transplantation, Sir Ganga Ram Hospital, New Delhi from January 1996 to December 2019, from a prospectively maintained database. Their demographic data, duration of symptoms before presenting to the hospital and duration of stay before surgery in the hospital were noted along with cause and level of obstruction. The type of procedure, any post-operative complications, mortality or re-exploration were also noted. Post-operative complications were graded as per Clavien Dindo classification. The data were compared with those published from westerncountries as well as from India.

\section{Statistical analysis}

Numeric continuous data was expressed as arithmetic mean \pm standard deviation for symmetrical data and median for asymmetrical data. Difference of means was tested using unpaired Student t-test or Mann Whitney $\mathrm{U}$ test depending upon the distribution. Nominal data was expressed as frequencies or proportions. SPSS17 was used for analysis and a $p$ value of $<0.05$ was considered to be significant.

\section{Results}

A total of 986 patients presented with intestinal obstruction during this period out of which 243 patients were managed conservatively and 743 patients underwent surgery. There were $429(57.74 \%)$ males and $314(42.26 \%)$ females who had a mean age of 50.1 years (range 11 to 96 years). The largest number of patients were in the age group of $41-60$ years (133 of $380,35 \%$ ).

\section{Etiology}

Adhesive obstruction was the most common cause in 273 (36.7\%) followed by carcinoma in 130 (17.5\%). Tuberculosis was present in $111(14.9 \%)$ and strictures of the intestine in 94 patients $(12.7 \%)$. Hernia accounted for only $5.4 \%$. A few presented with intussusception, volvulus and vascular disorders which is showed in Table 1. 
Among the patients admitted with adhesive obstruction, 93 (34\%) patients had not undergone any previous surgery. Colorectal surgery was the most common procedure preceding adhesive obstruction in 85 patients followed by small bowel surgery in 43 patients. A smaller number of patients had hepatobiliary, upper gastrointestinal and gynaecological surgery preceding adhesive obstruction as outlined in Table 2.

A total of 130 patients had carcinoma as the cause of intestinal obstruction of whom 75 (57.7\%) had colonic cancer. Gynaecological malignancy led to obstruction in 17 cases and carcinoma of the stomach in 12 patients. Some patients had gall bladder and jejunal carcinoma as shown in Table 3.

Strictures of the intestine were the cause for intestinal obstruction in 94 patients. These were possibly due to ischemia in 26 patients (with equal numbers found in the jejunum and ileum), tuberculosis in 16 patients (14 in ileum and 2 in jejunum) and preceding abdominal trauma in 14 patients (6 of whom had a stricture in the ileum and 2 in the jejunum). Radiation and pancreatitis were responsible for stricture in 12 patients each being localized in the splenic flexure or transverse colon in all patients with pancreatitis. Other less common causes were diverticulitis and crohn's disease. In 10 patients, the cause was not found.

Hernia was responsible for obstruction in 40 patients. 14 patients had obstructed ventral, 13 had incisional hernias, 8 parastomal hernias and 5 patients had internal herniation with adhesions.

In fifteen patients, intussusception was the etiology with the ileocaecal segment involved in 9 and ileoileal intussusception in 4 patients. The jejunum and transverse colon were involved in 1 patient each. 12 patients presented with volvulus with an ileal loop involved in 6 patients and the sigmoid colon and caecum in 3 patients each.

\section{Site}

The ileum was the most common site of obstruction in 329 (44.3\%) patients with the ileo-caecal region involved in 76 (10.3\%). The jejunum was involved in 109 (14.7\%) patients. Primary colonic involvement, apart from the ileo-caecal region, was present in 98 patients (13.2\%). 70 patients had carcinomatosis with diffuse peritoneal and visceral involvement and 55 patients had diffuse adhesions.

\section{Presentation}

The median time from the onset of the first symptoms to presentation in our hospital was 6 days (range 1-90) and themean duration of stay in hospital before surgery was 3.5 days (range 0-28).

More patients underwent surgery for a benign as compared to a malignant etiology (78.5\% vs $21.5 \%)$. In all patients with malignant cause, diagnosis was established before surgery. Patients with malignancy had a higher mean age (53.4 vs. 49.1 years), longer duration of symptoms before admission (median 13 vs. 8 days) and a higher mortality (10.7\% vs. $4.1 \%$. P value 0.03$)$ but their postoperative stay was similar. 
226 (30.4\%) patients had a comorbid illness before surgery. Hypertension, coronary artery disease and diabetes mellitus were the three most common comorbid conditions present in the patients in this study group. Compared to patients without any comorbidities, patients with comorbidities had a higher mean age (59.6 vs. 47.4 years), higher postoperative complication rate $(42.6 \%$ vs. $30.5 \%)$ and a higher mortality $(7.9 \%$ vs. $4.6 \%, P=0.4)$

\section{Procedures}

Overall 411 patients underwent some form of resection and anastomosis procedure while 183 patients had stoma. Adhesiolysis was the most common surgical procedure performed in 189 patients (Table 4) being the only procedure done in 88 and accompanied by a resection procedurein 81 patients.

\section{Postoperative complications}

$34.5 \%$ (257 of 743) patients had postoperative complications. Grade I complications were seen in 137 (53.3\%), grade II in 59 (22.9\%) patients. Grade Illa complications were seen in 27 (10.5\%), while IIlb in 25 (9.7\%) patients and grade IVa complications in 9 (3.5\%) patients. Prolonged ileus was the most common in 42 patients followed by wound infection in 36 patients. 6 patients had a repeat episode of obstruction during the same admission. Acute renal failure, fever, intra-abdominal bleeding occurred in 18 patients each. 25 patients required re-exploration in the postoperative period 9 for recurrent obstruction, 9 had post-operative anastomotic leak, 3 for intra-abdominal bleeding, enterocutaneous fistula, burst abdomen and stoma site obstruction in 1 patient each and 1 underwent pancreatic necrosectomy. 8 patients had new onset arrhythmia postoperatively. Patients who had complications had a higher mean age (51.7 vs. 47 years) and had a longer postoperative stay (11.8 days vs. 6.8 days) than those who did not.

\section{Mortality}

The overall operative mortality was $5.51 \%$ (41 of 743) with sepsis and multi-organ failure being the most common cause. Patients who died were older with a mean age of 55.3 years and more likely to have malignancy, strangulation and perforation (Table 5), but only the differences in outcome of the groups with malignancy and strangulation reached statistical significance on univariate analysis (Table 6).

\section{Discussion}

Intestinal obstruction remains one of the commonest causes of acute abdomen worldwide amounting to $5 \%$ of emergency admission. The pattern of intestinal obstruction varies from country to country and time to time with in a same country. A steady rise in the number of major abdominal operations, together with earlier diagnosis and elective treatment of groin hernias and intra-abdominal malignancy, has resulted in a dramatic change in the spectrum of intestinal obstruction faced in Western society and other developed countries over the past 50 years, when strangulated hernias accounted for half of the total case. In under developed and developing countries the ratio of volvulus and strangulated hernia is still high. Changes in the etiology of intestinal obstruction have been reported in developing countries over the last few years, 
and adhesion tends to be the most common cause in both the Western world and parts of Asia and the Middle East. ${ }^{[10]}$

Our patients differ from the west in various ways. For instance their mean age of was 50.1 years (range 11 weeks to 96 years) compared with 66.8 year in the west, while most of our patients (35.7\%) being between 40 and 60 (although they were slightly older than the patients in other reports from developing countries where the mean age was39.6 years) ${ }^{[11,12,13]}$.

Older studies, especially from the developing world, report a male predominance of the order of 2:110, possibly because the main cause of obstruction, hernia is more prevalent in males. ${ }^{[10,14]}$ With adhesive obstruction now becoming more frequent, this gender difference has decreased. In our study, $57.6 \%$ of patients were males as compared to $42.4 \%$ females. Studies from other centers in this region have also shown similar trends with males outnumbering females. ${ }^{[13,15]}$ However in the west, male-female ratio is nearly equal with only isolated reports of a male predominance. Fevang et al in their study have reported the proportion of females with intestinal obstruction increasingfrom $29 \%$ in 1960 to more than $40 \%$ in 1990. [9]

Around the turn of the century, adhesive obstruction became the most common cause of intestinal obstruction with only a few isolated studies still showing obstructed hernia to be more common. ${ }^{[12]}$ However in the developing world, though the incidence of adhesive obstruction has been showing a steady increase, most centers still report strangulated and obstructed hernia to be the most common cause of intestinal obstruction. Bjorg et al in study of over 35 years have shown that the incidence of adhesions increased from $43 \%$ to $53 \%$ while that of incarcerated hernia decreased from $41 \%$ to $24 \% .{ }^{[9]}$ In India, a study from Chandigarh described adhesions to be the cause in $27 \%$ patients compared to obstructed hernia in $22 \%$, while a study from Calcutta reported obstructed hernia to be more common (35.9\%) and from Pondicherry, of 572 patients reported, external hernia was seen $38 \%$ as compared to adhesive obstruction in $32 \%$. ${ }^{[13,16]}$

Results from other developing countries have also shown variable results. Akgun $\mathrm{Y}$ et al from Turkey reported volvulus to be the most common cause in $28.6 \%$ patients followed by $25.3 \%$ for adhesions. ${ }^{\text {[21] }}$ Two studies from Pakistan reported adhesions and tuberculosis as the most common causes. ${ }^{[10,12]}$ Recent reports from Jordan and Turkey have shown adhesions to be the most common cause and the Nigerian and Ghanaian experience is that there is a decrease in the proportion of obstructed hernias but they are still the most common cause of intestinal obstruction. ${ }^{[14,17,18,21]}$ Advances in health care with more operations being performed electively for hernia have decreased the number of emergencies and hence the incidence of obstruction episodes.

However developed countries have uniformly reported adhesive obstruction to be the most common cause of intestinal obstruction, with the more recent studies reporting rates of $60-75 \% .^{[1,2,3,4]}$ 
Colorectal operations were the most common procedures preceding adhesive obstruction in 85 patients followed by small bowel surgery in 43 patients out of a total number of 273 . Barmparaset al opined that the incidence of adhesive obstruction depended on the type of previous surgery. ${ }^{[18]}$. Appendectomy and gynaecological procedures were reported to be the most common causes in analyses by Malik et al (60\%) and Cox et al (23\%). ${ }^{[9,12,19]}$ Similar to our study, most western institutions report colorectal surgery to be the most common surgery preceding adhesive obstruction. ${ }^{[11,14]}$

The second most common cause in our patients was malignancy which was present in 130 (17.5\%) patients. Developed countries have also reported carcinoma to be the second most common cause after adhesions with an incidence of approximately $20 \% .{ }^{[22]}$ Carcinoma causes obstruction via various mechanisms but carcinomatosis was the most common cause in 70 patients with 35 patients having luminal growths and 37 having local recurrence with adjacent intestinal loops infiltrated/ adhered. Yemlaz et al also identified malignancy as the cause in 102 patients of which 85 were colorectal in origin. [20]. Similarly Naseer et al reported malignancy as the second most common cause and colon as the site in 33 of 44 patients with malignancy. ${ }^{[10]}$ Karakoc et al compared two groups of patient during different era and found the incidence of carcinomatosis to increase from $3.26 \%$ in $1980-1985$ to $27.03 \%$ in 2000 2005. ${ }^{[23]}$

In our study tuberculosis was directly related to obstruction in $111(14.9 \%)$ patients but was also present in 34 patients with other causes. The western literature reports very few cases of obstruction due to tuberculosis even with the resurgence of the disease after the increase in HIV infection. However tuberculosis continues to be an important cause in Asian population. Bhansali et al in their study found tuberculosis as a cause in $15.5 \%$ cases. ${ }^{[24]} 42$ of 59 patients had disease localized to the ileocaecal region. Similar to study by $\mathrm{Vij}$ et al the effected population is young with the disease localized mainly to the ileocaecal region. ${ }^{[25]}$

$94(12.7 \%)$ patients were diagnosed with non-specific strictures of the intestine. Salem et al reported these strictures in $8.3 \%$ of their patients with intestinal obstruction. A recent study from India has reported these strictures to be the cause in $27.2 \%$ although the exact cause is not known ischemia might be the most common etiology with most strictures localized to ileum and jejunum. ${ }^{[27]}$ Lalwani et al from our department have also shown the ileum to be the most common site in patients with post-traumatic strictures which probably develop after the segmental blood supply is compromised after injury to the mesenteric vessels. ${ }^{[28]}$ Since malignancy was a frequent cause, adjuvant radiation treatment was responsible for strictures in 12 patients. Pancreatitis was the preceding etiology in 12 patients. Aldridge et al reported pancreatitis as the cause for strictures, with 8 of the 10 strictures located in the splenic flexure and transverse colon. [29]

The ileum was the most common site for intestinal obstruction in $329(44.3 \%)$ with the colon involved in $98(13.2 \%)$ patients. In our experience the small bowel was the more frequent site of obstruction as reported in other studies. 
Patients with malignancy compared with those who had benign conditions had a higher mean age (53.4 vs. 49.1 years), equivalent male to female ratio, a longer interval between the onset of symptoms and presentation to hospital (13 vs. 8 days). Their mortality rates were also higher $(10.7 \%$ vs. $4.1 \%$. p value 0.03 ) but their postoperative stay was similar.

$226(30.4 \%)$ patients had associated comorbidities before surgery. The mean age of these patients was higher at 59.6 years compared to those who were free of other disease conditions (47.4). These patients with comorbidities had longer postoperative stays ( 9.6 days) compared to without ( 7.4 days). Fevang et al and Kapan et al in their study on intestinal obstruction have reported the presence of preoperative comorbidities to be a predictor of death but in our study although their mortality was higher it was not statistically significant. ${ }^{[9,14]}$

Postoperative complications occurred in 257 (34.5\%) patients, which is the same as in the study from Asbun et al who also found complications in $31 \% .{ }^{[30]}$ The most common complication was postoperative ileus in 42 patients. 6 patients had a second episode of subacute intestinal obstruction. Wound infection was present in 36 patients. Most studies mention systemic complications and wound infection to be the most common complications. Re-exploration was required in 25 patients with 9 patients undergoing surgery for adhesions and one each for intra-abdominal bleeding, enterocutaneous fistula and pancreatic necrosis.

The mortality rate in our study was $5.51 \%$ which is comparable to other studies reporting between 2.0 to $11 \% .{ }^{[31,32]}$ The patients who died were older, more likely to have malignancy and intestinal strangulation. ${ }^{[33]}$ Bjorg et al found old age, comorbidities, nonviable strangulation, and a treatment delay of more than 24 hours increased the death rate. ${ }^{[9]} \mathrm{Ti}$ and Yong also reported increasing age, gangrene and malignancy to be associated with higher mortality rates. ${ }^{[34]}$ Strangulation and malignant etiology are the two most significant factors for mortality in our study with sepsis being the most common cause of death. 8 patients had new onset arrhythmia ( 6 had atrial fibrillation and 2 had supra-ventricular tachycardia). A recent study has shown that new onset $\mathrm{AF}$ in sepsis is associated with higher mortality. ${ }^{\text {[35] }}$

\section{Conclusions}

Compared to previous reports, post-operative adhesions are now a common cause of intestinal obstruction in developing countries especially in referral centers. The most common preceding surgery is on the colon and rectum. The mortality rate is also comparable with those reported from the west. Old age, malignancy and strangulation were associated with a higher risk of mortality as is the experience in other centers. The developing world, however still has some differences in that the patient population is younger, males predominate and tuberculosis continues to be an important cause for intestinal obstruction.

\section{Declarations}


1. Ethics approval and consent to participate: Ethical committee approval was not needed as per the regulations of the local committee.

2. Consent for publication: Waiver of consent taken.

3. Availability of data and materials: All the data and material is available with the author.

4. Competing interest:

5. Funding: The research received no specific grant from any funding agency in public, commercial or not-for-profit sector.

\section{Authors' Contributions:}

a. Dr Suvendu Sekhar Jena - Data collection and analysis, Writing full article.

b. Dr Ravi Chandra Reddy Obili - Data collection and analysis, Proofing of article.

c. Dr Sri Aurobindo Prasad Das - Study conceptualization and designing, Article proofing.

d. Dr Ruchir Bhavsar - Data Collection and Excel formulation.

e. Dr Sanket Solanki- Data collection and Excel formulation.

f. Dr Samiran Nundy - Final proofing of article and final approval.

\section{Acknowledgements:}

a. Parmanand Tiwari - Junior Executive.

b. Anju Sharma - Data Entry Operator.

\section{References}

1. Miller G, Bomana J, Shrier I, Gordon PH. Etiology of small bowel obstruction. Am J Surg. 2000;180(1): 33-6.

2. Chen XZ, Wei T, Jiang K, Yang K, Zhang B, Chen ZX et al. Etiological factors and mortality of acute intestinal obstruction: a review of 705 cases. Zhong Xi Yi Jie He XueBao. 2008;6(10):1010-6.

3. Shelton BK. Intestinal obstruction. AACN Clin Issues. 1999;10(4):478-91.

4. Ellis $\mathrm{H}$. The causes and preventions of intestinal adhesions.Br J Surg 1982;69: 241-3.

5. Scudder CL. Principles underlying treatment of acute intestinal obstruction. Trans NH Med Soc 1908:234.

6. Fevang BT, Fevang J, Stangeland L, Soreide O, Svanes K, VisteA. Complications and death after surgical treatment of small bowel obstruction. A 35-year institutional experience. Ann Surg. 2000; 231(4): 529-37.

7. Cross KS, Johnston JG. Small bowel obstruction: a review of 456 cases in a west of Ireland region. J R Soc Med. 1987 Mar;80(3):149-50.

8. Popoola D, Lou MA, Mansour AY, Sims EH. Small bowel obstruction: review of nine years of experience Los Angeles, California. J Natl Med Assoc. 1984; 76(11):1089-95

9. Fevang BT, Fevang J, Lie SA, Søreide O, Svanes K, Viste A. Long-term prognosis after operation for adhesive small bowel obstruction. Ann Surg. 2004;240(2):193-201. 
10. Baloch NA, Mohammad D, Qureshi SA. Current pattern of mechanical intestinal obstruction in adults. Journal of Surgery Pakistan (International).2011;16 (1) :38-40.

11. Kössi J, Salminen P, LaatoM. The epidemiology and treatment patterns of postoperative adhesion induced intestinal obstruction in Varsinais-Suomi hospital district.Scand J Surg. 2004;93(1):68-72.

12. Malik AM, Shah M, Pathan R, Sufi K. Pattern of acute intestinal obstruction: is there a change in the underlying etiology? Saudi J Gastroenterol. 2010;16(4):272-4.

13. Sinha S, Kaushik R, Yadav TD, Sharma R, Attri AK. Mechanical bowel obstruction: the Chandigarh experience.Trop Gastroenterol. 2002;23(1):13-5.

14. Kapana M, Ondera A, Polata S, Aliosmanoglua I, Arikanoglua Z, Taskesena F et al. Mechanical bowel obstruction and related risk factors on morbidity and mortality. Journal of Current Surgery. 2012;2(2): 5561.

15. Adhikari S, Hossein MZ, Das A, Mitra N, Ray U. Etiology and outcome of acute intestinal obstruction: A review of 367 patients in eastern India. Saudi J Gastroenterol. 2010;16(4): 285-7.

16. Tamijmarane A, Chandra S, Smile SR. Clinical aspects of adhesive intestinal obstruction. Trop Gastroenterol. 2000;21(3):141-3.

17. Oladele AO, Akinkuolie AA, Agbakwuru EA. Pattern of intestinal obstruction in a semiurban Nigerian hospital. Niger J ClinPract. 2008;11(4):347-50.

18. Barmparas G, Branco BC, Schnüriger B,Lam L, Inaba K, Demetriades D. The incidence and risk factors of post-laparotomy adhesive small bowel obstruction. J Gastrointest Surg. 2010;14(10):1619-28.

19. Cox MR, Gunn IF, Eastman MC, Hunt RF, Heinz AW. The operative etiology and types of adhesions causing small bowel obstruction. Aust N Z J Surg. 1993;63(11):848-52.

20. AkgunY, Yilmaz G, Akbayin H. Causes and Effective Factors on Mortality of Intestinal Obstruction in the South East Anatolia. Turk J Med. 2002; 32:149-54.

21. Omari AH, Alkhatib LL, Khammash MR Changing pattern of intestinal obstruction in northern Jordan.World J Surg. 2012;36(2):437-40.

22. Miller G, Boman J, Shrier I, Gordon PH. Small-bowel obstruction secondary to malignant disease: an 11-year audit. Can J Surg. 2000;43(5):353-8.

23. Karakoc D, Memis A, Sayek I. Intestinal obstructions: what has changed so far? Int Surg. 2009;94(4):344-49.

24. Bhansali SK. Abdominal tuberculosis. Experiences with 300 cases. Am J Gastroenterol 1977;67: 32437.

25. Vij JC, Malhotra V, Choudhary V, Jain NK, Prasad G, Chaudhary A, et al. A clinicopathological study of abdominal tuberculosis. Indian J Tubercul. 1992;39:213-20.

26. Shaikh SM, Dholia KR, Soomro SH, Abro AA, Shaikh SA, Ali S. Current spectrum of acute intestinal obstruction at CMC Larkana. 2010;16(2): 295-9.

27. Jain BK, Agrawal J, Rathi V, Garg PK, Dubey IB.Subacute intestinal obstruction: an enigma revisited. Trop Doct. 2013;43(1):5-8.

28. Lalwani S , Gupta M, Varma V, Mehta N, Kumaran V, Nundy S. Small bowel stricture following blunt abdominal trauma. Trop Gastroenterol. 2011;32(4):304-8.

29. Aldridge MC, Francis ND, Glazer G, Dudley HA. Colonic complications of severe acute pancreatitis. $\mathrm{Br}$ 
J Surg. 1989;76(4):362-7.

30. Asbun HJ, Pempinello C, Halasz NA. Small bowel obstruction and its management. IntSurg 1989;74:23-7.

31. Lo OS, Law WL, Choi HK, Lee YM, Ho JW, Seto CL. Early outcomes of surgery for small bowel obstruction: analysis of risk factors. Langenbecks Arch Surg. 2007;392(2):173-8.

32. Margenthaler JA, Longo WE, Virgo KS, Johnson FE, Grossmann ME, Schifftner TL et al. Risk factors for adverse outcomes following surgery for small bowel obstruction. Ann Surg. 2006; 243(4): 456-64. 33. Uludag M, Akgun I, Yetkin G, Kebudi A, Işgor A, Sener A. Ulus Travma Acil Cerrahi Derg. Factors affecting morbidity and mortality in mechanical intestinal obstruction.2004;10(3):177-84.

34. Ti TK, Yong NK. The pattern of intestinal obstruction in Malaysia. Br J Surg. 1976;63(12):963-5. 35. Lee-lannotti JK, Capampangan DJ, Hoffman-Snyder C,Wellik KE, Patel B, Tondato F et al. New-onset atrial fibrillation in severe sepsis and risk of stroke and death: A critically appraised topic. Neurologist. 2012;18(4):239-43.

\section{Tables}

Table 1. Aetiology of intestinal obstruction 


\begin{tabular}{|lll|}
\hline Aetiology & $\begin{array}{l}\text { Number of patients } \\
(n=743)\end{array}$ & $\%$ \\
\hline Adhesive obstruction & 273 & 36.7 \\
\hline Carcinoma & 130 & 17.5 \\
\hline Tuberculosis & 111 & 14.9 \\
\hline Stricture of intestine & 94 & 12.7 \\
\hline Hernia & 40 & 5.4 \\
\hline Intussusception & 15 & 2 \\
\hline Perforation of gut & 13 & 1.7 \\
\hline Volvulus & 12 & 1.6 \\
\hline Crohn'sdisease & 7 & 0.9 \\
\hline Blind loop syndrome & 3 & 0.4 \\
\hline Vascular disorders & 12 & 1.6 \\
\hline Meckel's diverticulum & 4 & 0.5 \\
\hline Faecolith & 4 & 0.5 \\
\hline Ladd's band & 5 & 0.7 \\
\hline Miscellaneous & 20 & 2.67 \\
\hline
\end{tabular}

Table 2. Operations preceding adhesive intestinal obstruction 


\begin{tabular}{|lll|}
\hline No & Surgery & No. (\%) \\
\hline 1. & Colorectal & $85(31.1)$ \\
\hline 2. & Small bowel & $43(15.8)$ \\
\hline 3. & Hepato-biliary & $13(4.8)$ \\
\hline 4. & Upper Gl & $13(4.8)$ \\
\hline 5. & Gynaecological & $11(4)$ \\
\hline 6. & Hernia repair & $9(3.3)$ \\
\hline 7. & Liver transplant & $4(1.5)$ \\
\hline 8. & Peritoneal disease & $2(0.7)$ \\
\hline 9. & No previous surgery & $93(34)$ \\
\hline & Total & 273 \\
\hline
\end{tabular}

Table 3: Site of malignancy as primary cause for intestinal obstruction

\begin{tabular}{|c|c|c|}
\hline No. & Site of malignancy & No of patients(\%) \\
\hline \multirow[t]{6}{*}{1.} & Colon & $75(57.7)$ \\
\hline & - Ileocaecal & - $\quad 25$ \\
\hline & - Rectal & - 24 \\
\hline & - $\quad$ Sigmoid & - 16 \\
\hline & - Transverse colon & - 6 \\
\hline & - Descending colon & - 4 \\
\hline 2. & Gynaecological & $17(13.1)$ \\
\hline 3. & Stomach & $12(9.2)$ \\
\hline 4. & Gall bladder & $10(7.7)$ \\
\hline 5. & Peritoneum & $10(7.7)$ \\
\hline \multirow[t]{2}{*}{6.} & Jejunum & $6(4.6)$ \\
\hline & Total & 130 \\
\hline
\end{tabular}

Table 4. Surgical procedures 


\begin{tabular}{|c|c|c|}
\hline No. & Procedure & No of patients \\
\hline \multirow[t]{6}{*}{1.} & Adhesiolysis & 189 \\
\hline & - Adhesiolysis alone & $\cdot 88$ \\
\hline & - Adhesiolysis with resection & - $\quad 81$ \\
\hline & - $\quad$ Adhesiolysis with bypass & $\cdot$ \\
\hline & - $\quad$ Adhesiolysis with stricturoplasty & $\cdot$ \\
\hline & - $\quad$ Adhesiolysis with other intervention & $\cdot 9$ \\
\hline \multirow[t]{3}{*}{2.} & Ileal resection and anastomosis & 108 \\
\hline & Ileal resection with ileostomy & 48 \\
\hline & Ileostomy & 40 \\
\hline \multirow[t]{3}{*}{3.} & Jejunal resection and anastomosis & 80 \\
\hline & Jejunostomy & 41 \\
\hline & Jejunal resection with colectomy & 1 \\
\hline \multirow[t]{5}{*}{4.} & Right hemicolectomy & 76 \\
\hline & Right hemicolectomy with ileostomy & 23 \\
\hline & Left hemicolectomy & 26 \\
\hline & Sigmoidectomy & 40 \\
\hline & Anterior resection with ileostomy & 31 \\
\hline \multirow[t]{2}{*}{5.} & Miscellaneous & 40 \\
\hline & Total & 743 \\
\hline
\end{tabular}

Table 5. Mortality group vs. Survivors 


\begin{tabular}{|llll|}
\hline No & Parameters & $\begin{array}{l}\text { Mortality } \\
\mathrm{n}=41\end{array}$ & $\begin{array}{l}\text { Survivors } \\
\mathrm{n}=702\end{array}$ \\
\hline 1 & Mean age (years) & 55.3 & 49.86 \\
\hline 2 & Malignant aetiology & $17(41.5 \%)$ & $139(19.8 \%)$ \\
\hline 3 & Duration of symptoms before admission(median) & 5.3 days & 6 days \\
\hline 4 & Comorbidities & $7.9 \%$ & $4.6 \%$ \\
\hline 5 & Strangulation & $7(33.3 \%)$ & $35(9.7 \%)$ \\
\hline 6 & Postoperative stay(mean) & 13.85 days & 8.6 days \\
\hline
\end{tabular}

Table 6. Univariate analysis of factors predicting mortality

\begin{tabular}{|lll|}
\hline No & Mortality predictors & $p$ value \\
\hline 1 & Age $>75$ & 0.11 \\
& Age $<75$ & \\
2 & Strangulation / Viable bowel & 0.01 \\
\hline 3 & Benign/Malignant & 0.02 \\
\hline 4 & Co-morbidity & 0.21 \\
\hline
\end{tabular}

